\title{
The Proof is in the Pronoun: Grammatical and Semantic Gender in Anglo Saxon
}

\begin{abstract}
By John M. Ryan*
In the literature on gender systems, anaphoric pronouns are commonly given the proverbial backseat to nouns and even nominal modifiers such as adjectives; however, as this paper will point out, in the case of Old English, the pronominal system played a major role in the development of the gender system that we employ today. Following Curzan (2003), who draws on the Helsinki corpus of Old English texts, this paper will demonstrate how the pronominal gender system in Old English, like its Modern counterpart today, might very well serve as a window to the mind of the Old English speaker and what s/he perceived as "natural" gender. I will show how the pronominal gender system of Old English has in actuality evolved very little into Modern English. I will argue that in Old English for nouns there were two very distinct gender systems: 1) grammatical (e.g., wif [neuter] "woman"); and 2) semantic (or "natural") (e.g., modor [feminine] "mother"), that operated simultaneously. For Old English pronouns, however, I suggest a more complex gender system than for nouns, one that: 1) preferred/ selected "natural" gender pronouns for human or human-like referents despite the grammatical gender of the referent; and 2) preferred/selected grammatical gender for non-human or inanimate referents throughout the Old English period, ultimately gravitating toward overall preference for natural, or semantic, gender by the early Middle English period. I will term this system pronominal complexity and show how this has major implications on how natural gender in Modern English evolved.
\end{abstract}

Keywords: Diachronic linguistics, Gender, Old English, Pronouns

\section{Introduction}

Languages that sprout from the Indo-European family tree have descended into modern times with differing arrangements of gender or noun classes ${ }^{1}$. Some have retained all three Late Proto-Indo-European (LPIE) grammatical genders of masculine, feminine, and neuter. Others, for varying reasons, have lost one of the three. Still other languages, like Modern English (and the reason for this paper), have lost all their historical affiliation with grammatical gender in nouns and assumed a "natural" interpretation of gender as evidenced when they appear with corresponding anaphoric pronouns ${ }^{2}$, as exemplified in (1) through (3):

1. John (masculine referent) bought his (masculine anaphoric pronoun) car in Florida.

\footnotetext{
* Associate Professor of Spanish Linguistics, Department of Hispanic Studies, University of Northern Colorado, USA.

${ }^{1}$ In this paper it is important to distinguish between the terms "gender" and "noun class". Gender distinctions have some basis, either natural or arbitrary, on sex; and 2) Noun class distinctions have no basis whatsoever on sex. As Matasovic (2004) points out, noun class systems across world languages have been found to be based on other such concepts as animacy, shape, etc. This dichotomy allows us to specify systems in languages that possess large numbers of noun classes.

2 Exceptions to this generality are few (e.g., anaphoric "she" referring to ships, machines, and countries, and, as Matasovic points out, "he" or "she" referring to pets, although in my opinion this does not break the natural gender rule because this use does indeed correspond to the natural sex of the particular pet).
} 
2. Mary (feminine referent) bought her (feminine anaphoric pronoun) car in Philadelphia.

3. John bought a car (neuter referent) and lent it (neuter anaphoric pronoun) to Mary.

This paper has four goals: 1) to provide a typological framework for gender systems across multiple languages, starting with a comparison among languages overall, to be followed by a study of the Indo-European languages, and finishing specifically with the Germanic languages; 2) to investigate the historical shift from grammatical to natural gender in English, in both nouns and pronouns; 3) to argue for a similarity between the gender systems of Early Proto-Indo-European and Modern English with regards to semantic "transparency"; and 4) to conclude with a summary of findings and to suggest whether certain gender shifts that have happened diachronically across languages have been either semantically or socially motivated, or both.

Most importantly, in terms of gender in Old English, this paper will argue how consideration of the pronominal gender system of Old English, like its Modern counterpart today, is necessary to the overall picture of gender and might very well serve as a window to the mind of the Old English speaker and what s/he perceived as "natural" gender.

\section{Typology and Work on Gender Systems}

\section{Typology According to Gender}

Linguists have always been interested in gender as a grammatical category since the earliest days of inquiry, having first been treated by the Greeks such as Pythagoras ${ }^{3}$, Aristotle, and Dionysius Thrax. The past thirty years have witnessed more comparative studies of gender systems across languages. Undoubtedly, the two most important and exhaustive of these are the pioneering work of Corbett (1991) and more recently, Matasovic (2004).

Corbett's treatment of gender is a seminal work from a typological standpoint. In his work, Corbett both: 1) defines gender for purposes of typological comparison; and 2) establishes five (5) typological parameters that can be used to compare gender systems across languages.

According to Corbett, gender is unlike other grammatical categories such as case or number that can vary according to the particular need of the speaker or affect the meaning of the noun in some way. Corbett defines gender as a unique grammatical category, again unlike case or number, that has to be specified in a person's lexicon, either by general assignment principles or individually for specific nouns.

Corbett further explains that one can spot gender systems in languages where nouns tend to have the following two properties: 1) nominal classification-

\footnotetext{
${ }^{3}$ Pythagoras was the first to classify nouns according to notions of gender.
} 
whereby nouns of a language typically belong to a closed set of noun classes; and 2) agreement - whereby the gender of the noun determines the form that other words take in the sentence, thereby forming some kind of syntactic unit.

Corbett goes on to explain that some languages have gender and others do not. He further specifies that for all languages having gender systems there exists a semantic core of nouns for which gender can be predicted solely from meaning. All other nouns of a given language, for which gender cannot be predicted from meaning alone, are considered part of the semantic residue. Languages differ widely as to the extent to which nouns belong to the semantic core or the semantic residue. Some languages, such as the Dravidian languages, have all their nouns exclusively within the semantic core so in every case gender can be predicted by meaning. Other languages for the most part do not work this way, and their nouns are divided in some ratio between the core and residue.

According to Corbett, another important concept related to the notion of semantic core and residue is that of gender assignment, whether on a semantic basis for nouns in the core, or formally (morphologically or phonologically) for nouns in the residue. In other words, the gender of nouns in the semantic core can be predicted, as we have already seen, on the basis of meaning, whereas the gender of those in the residue can be predicted to the noun class or declension they belong to. Of course, there are always exceptions where nouns may be formally declined according to a specific class and have a gender atypical of that class.

Drawing on both Corbett and Matasovic, Table 1 provides five typological parameters to help compare gender systems across languages:

Table 1. Typological Parameters for Gender Systems

\begin{tabular}{|l|l|} 
Parameter & \multicolumn{1}{|l|}{ Definition } \\
\hline (1) Overt/covert & $\begin{array}{l}\text { Whether gender marking appears or not on nouns } \\
\text { themselves or just on the words in the utterance the } \\
\text { noun agrees with. }\end{array}$ \\
\hline $\begin{array}{l}\text { (2) Number of genders } \\
\text { principles }\end{array}$ & $\begin{array}{l}\text { Gender systems vary as to the number of genders they } \\
\text { include. The minimal number is two; the largest is } \\
28 .\end{array}$ \\
\hline $\begin{array}{l}\text { (4) Scope of gender } \\
\text { agreement }\end{array}$ & $\begin{array}{l}\text { The gender of every noun in a language cannot be } \\
\text { predicted. However, the gender of some nouns } \\
\text { (semantic core) can be predicted. }\end{array}$ \\
\hline (5) Default gender & $\begin{array}{l}\text { Languages vary as to how extensive gender } \\
\text { agreement occurs for a noun in an utterance. }\end{array}$ \\
\hline
\end{tabular}

Source: Corbett 1991, Matasovic 2004.

These parameters provide some tools that can help to make typological assessments regarding gender about any language. 


\section{Gender around the world}

Perhaps the most basic task of a typological review of language gender systems is an overall distinction between languages or language families as to whether those languages have gender or not. To do this, a combined genetic and areal division is necessary because, as Matasovic (2004) points out, in more than one case some language families may have picked up unexpected gender or non-gender tendencies of neighboring languages families. Matasovic starts with an overall genetic classification of language families, indicating what general tendencies these families have as to the presence or absence of gender (e.g., Indo-European and Caucasus families tend to have gender, Austro-Asiatic languages tend to be genderless), but he then develops his presentation into an areal configuration that helps explain why some languages do not follow the characteristic gender for their particular language family:

A) Northern Eurasia-As will be seen later in this paper, most IndoEuropean languages have gender. Those that moved from Northern Eurasia into areas that are contiguous with genderless languages, lost gender completely (e.g., Armenian, Persian, and some other Western Iranian languages). Other Northern Eurasian languages are genderless: Basque, Uralic, Tungusic, Turkic, Mongolian, Chukchi-Kamchatkan, Korean-Japanese-Okinawan, Ainu, Sino-Tibetan, and Eskimo Aleut.

B) Caucasus-Most of the North East Caucasus languages have gender systems, as do two of the five North West languages. It is completely absent in the four languages of the third family, the Kartvelian.

C) Indian Subcontinent-Nearly all the languages in this geographical area have gender by default (with the exception of Brahui). Even the Munda languages of the Austroasiatic family (typically genderless) that find themselves geographically located in this area have gender.

D) Southeast Asia-All languages and language families in this area tend to be genderless.

E) Africa-About two thirds of these languages have gender. They can range from two (masculine and feminine) in the Afro-Asiatic languages to over twenty as in the Niger-Congo languages.

F) Australia-Most languages have gender. Many show marking on the verb.

G) New Guinea-These languages have gender.

$\mathrm{H})$ Oceania-Most languages in this region tend to be Austronesian and they do not have gender.

I) Pacific Cost of North America-These languages have gender.

J) Interior and East North America-These languages have gender.

K) Amazonia-These languages have gender.

L) Pacific Coast of South America—These languages lack gender systems.

Despite the patterns evidenced above, typologists would still agree that there is a rather unexpected distribution of gender-present versus gender-absent languages throughout the world. 


\section{$\underline{\text { Gender in Indo-European languages }}$}

Matasovic (2004) was instrumental in narrowing the typological focus of gender systems in Indo-European languages. He has established four possible paths that modern Indo-European languages have taken since their late maternal prototype with regard to gender (Table 2):

A) Preservation of all three genders (masculine, feminine, and neuter).

B) Merger of masculine and neuter genders (sometimes with leaks of old feminine into neuters).

C) Merger of masculine and feminine genders (sometimes with leaks into neuters).

D) Complete loss of gender (sometimes with the preservation of a pronominal gender system, as in Modern English ${ }^{4}$.

Table 2. Resulting Gender Systems of Indo-European Languages

\begin{tabular}{|c|c|c|c|}
\hline$\frac{\text { Preservation of }}{\underline{\text { All } 3 \text { Genders }}}$ & 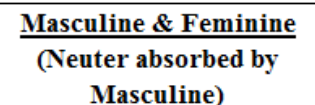 & $\begin{array}{l}\text { Masculine \& Neuter } \\
\begin{array}{c}\text { (Feminine absorbed } \\
\text { by Masculine) }\end{array}\end{array}$ & $\begin{array}{l}\text { Gender Loss } \\
\text { (with possible preservation } \\
\text { in pronouns) }\end{array}$ \\
\hline $\begin{array}{c}\text { Continental Celtic } \\
\text { Faroese } \\
\text { Gothic } \\
\text { Greek } \\
\text { Gujarati } \\
\text { Icelandic } \\
\text { Konkani } \\
\text { Marathi } \\
\text { Nynorsk } \\
\text { Old Albanian } \\
\text { Old and Middle Indic } \\
\text { Old English } \\
\text { Old French } \\
\text { Old Iranian } \\
\text { Old Irish } \\
\text { Old Italic } \\
\text { Old Norse } \\
\text { Old Prussian } \\
\text { Roshani } \\
\text { Shughni } \\
\text { Slavic } \\
\text { Sogdian } \\
\text { Some Flemish Dialects } \\
\text { Standard German } \\
\text { Yiddish }\end{array}$ & $\begin{array}{c}\text { Bactrian } \\
\text { British } \\
\text { Croatian dialect of Molise } \\
\text { East Baltic } \\
\text { Hindi } \\
\text { Karshmiri } \\
\text { Khwaresmian } \\
\text { Lahndi } \\
\text { Manx } \\
\text { Middle and Modern Irish } \\
\text { Modern Albanian } \\
\text { New Iranian } \\
\text { Rajasthani } \\
\text { Romance in general } \\
\text { Saka } \\
\text { Scottish } \\
\text { Sindhi } \\
\text { Sele Fara Slovenian } \\
\text { Some Indoaryan/Nuristani } \\
\text { Tocharian }\end{array}$ & $\begin{array}{l}\text { East Scandinavian } \\
\text { Frisian } \\
\text { Dutch }\end{array}$ & $\begin{array}{c}\text { Middle West Iranian } \\
\text { Modern West Iranian } \\
\text { Bengali } \\
\text { Assamese } \\
\text { Some N. Indo-Aryan } \\
\text { Greek dialects in Turkey } \\
\text { Middle \& Modern English } \\
\text { Afrikaans } \\
\text { Swedish dialects in Finland } \\
\text { Armenian } \\
\text { Latvian dialects in Estonia }\end{array}$ \\
\hline
\end{tabular}

Source: Matasovic 2004.

\footnotetext{
${ }^{4}$ The author is in disagreement with Matasovic's assertion that English has suffered a "complete loss of gender". As we shall see, loss of nominal inflection as well as presence already of a rather "weak" gender system has contributed to a leveling of any overt formal distinction of gender for most English nouns (exceptions exist in derivational forms such as actress where gender is still overtly expressed). But gender is still very prevalent in English, it just has shifted from a more formal to a more natural (and as I will argue, a more semantically transparent) system where all nouns are now part of the semantic core and their natural gender can be predicted exclusively from their meaning.
} 
Although the origins of a three-gendered system in Old English have been commonly attributed to Indo-European (Baldi 2011, Campbell 1983, Meillet 1970, Quirk and Wrenn 1957), there is some evidence that in its earliest days, IndoEuropean was in fact a language with just two noun classes: 1) common and 2) neuter (Matasovic 2004, Schwink 2004, Fortson 2005, Gray and Atkinson 2003). This theory ${ }^{5}$ goes on to say that within this earlier version of the proto-language, commonly referred to as Early or Pre-Proto-Indo-European, the distinction among noun classes was not one that was based on sex but rather animacy and a given noun class could be predicted according to its location on the following animacy continuum ${ }^{6}$.

\section{animate $>$ human $>$ non-human $>$ inanimate}

All things animate were expressed in the "common" noun class while everything else was considered inanimate and expressed in the "neuter" class. However, the neuter plural for some nouns had a special function as a collective or abstract singular and by the Late Proto-Indo-European period was even being used with singular verb forms. As time went on, this discrepancy in agreement caused a movement toward the creation of yet a third noun class which became affiliated with the feminine gender. Tichy (1993) demonstrates this point with the origin of the word for "widow" in Proto-Indo-European where for example, $\boldsymbol{h}_{1}$ widheweh $_{2}$ in Old Proto-Indo-European meant a collective "family of the killed one" or "those belonging to the killed one". This neuter plural noun form took a singular verb form. Tichy further explains that the singular verb may have facilitated a change in meaning to "the person (singular and feminine) belonging to the killed one", thus vidua (feminine) in Latin and modern English widow. Matasovic (2004) points out that as a result of this process many Late Proto-Indo-European feminine nouns correspond to Early Indo-European neuters which, in turn, have yielded feminine nouns in the daughter languages. Some examples follow:

\section{Proto-Indo-European}

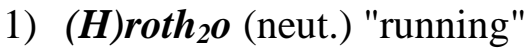

2) terso- (neut.) "dryness"

\author{
$\underline{\operatorname{Latin}}^{7}$ \\ rota $($ fem.) "wheel" \\ terra (fem.) "earth"
}

\footnotetext{
${ }^{5}$ Among the evidence for an earlier, two-gendered variety of Indo-European, Matasovic provides the following: 1) Hittite, pertaining to the Anatolian branch of the Indo-European family allegedly "broke away" from the rest of the family at an earlier period than the other branches, and perhaps that is why it possesses only two genders and more importantly, no trace of the remnants of a third gender (e.g., in the pronominal system), a phenomenon that is most common for languages that "lose" a gender (e.g., English, etc.); 2) In many Indo-European languages that have three genders there are adjectives that do not distinguish between masculine and feminine forms; and 3) In ProtoIndo-European the masculine and feminine share the same stem *se-/*so- for the demonstrative pronoun while the neuter stem is separate, *to-

${ }^{6}$ The author of this paper prefers the word "continuum" to "hierarchy", since the latter suggests primacy of some forms over others.

${ }^{7}$ Matasovic draws his examples from Latin and therefore those are provided here.
} 


\section{Gender in the Germanic languages}

Table 3 takes a closer look at how gender has evolved in the Germanic languages alone.

Table 3. Gender Systems in Germanic Languages

\begin{tabular}{|c|c|c|c|}
\hline$\frac{\text { Preservation of }}{\text { All 3 Genders }}$ & $\begin{array}{c}\frac{\text { Masculine \& Feminine }}{\text { (Neuter absorbed by }} \\
\text { Masculine) }\end{array}$ & $\begin{array}{c}\frac{\text { Deviating Group A }}{\text { Masculine \& Neuter }} \\
\text { (Feminine absorbed by } \\
\text { Masculine) }\end{array}$ & $\begin{array}{c}\frac{\text { Deviating Group B }}{\text { Gender Loss }} \\
\text { (Preservation in } \\
\text { pronouns) }\end{array}$ \\
\hline Faroese & & $\begin{array}{c}\text { East Scandinavian } \\
\text { Frisian } \\
\text { Gothic }\end{array}$ & $\begin{array}{c}\text { Middle \& Modern } \\
\text { English }\end{array}$ \\
Icelandic & Dutch & \\
Nynorsk & & \\
Old English & & & \\
Old Norse & & & \\
Some Flemish Dialects & & & \\
Standard German & & & \\
Yiddish & & & \\
Proto-Germanic & & & \\
\hline
\end{tabular}

Source: Matasovic 2004, Schwink 2004.

For the most part, as evidenced by the number of languages appearing in the first column of Table 3, an overwhelming tendency has been for the Germanic languages to inherit all three genders from Late Proto-Indo-European. However, there are two other trends that are specific to the Germanic family alone when it comes to the evolution of gender.

The first of these findings is that the distribution of gender systems within the Germanic languages, unlike other Indo-European language families, has no case where the neuter has been completely absorbed by the masculine gender, thereby rendering a strict masculine-feminine dichotomy (This evolutional path is one of the most highly represented by Romance and other language families of Indo-European heritage.).

The second case of specialized gender development in Germanic occurs in what the author of this paper will refer to Deviating Language Group A, consisting of East Scandinavian, Frisian, and Dutch languages, where masculine and feminine genders have merged to a "common" gender that coexists with a neuter gender (reminiscent of the Early Proto-Indo-European system as we shall see later in this paper).

The other evolutional possibility for the Germanic languages is that which the author of this paper will refer to as Deviating Language Group $\mathrm{B}^{8}$, represented by Middle and Modern English, where gender has shifted from a grammatical

\footnotetext{
${ }^{8}$ This particular deviation from the apparent norm of preserving the tri-partite Late Indo-European gender system is not so special in the broader perspective of overall Indo-European languages (Table 2) that have followed this path. However, the author points out that it is an important deviation for the Germanic languages because it is the only case where this happens for this language family.
} 
to natural representation. The remainder of this paper investigates Group B, i.e., the path taken by English .

\section{The Story of Gender in English Nouns}

Having discussed the tripartite gender system of Old English nouns and pronouns as well as the much reduced gender system of Modern English, the following section traces the development of gender systems from the earliest days of Early Proto-Indo-European to Modern English ${ }^{10}$.

\section{$\underline{\text { Gender in nouns from proto-Germanic to modern English }}$}

Table 3 showed the paths gender has taken in the Germanic family of languages with a clear preference for retention of all three late Proto-IndoEuropean genders, with Old English being no exception. So why would Middle and Modern English take such an extreme detour when it came to the gender system? According to Curzan (2003), how the gender system of Modern English arrived at its current state can be attributed to several linguistic factors, both internal and external, that probably simultaneously worked together to bring us the reduced configuration that we have today.

Internally speaking, Curzan explains that the Old English grammatical gender system was already "weak" and in a state of decline. She points out that the gender of Old English nouns was not predictable from their morphology (e.g., strong nouns ending in a consonant could belong to any three genders). Other evidence for a less-than-strong system is the existence of nouns that could be declined according to two or all three genders. Furthermore, as Kitson (1990) suggests, still other evidence exists that gender was a variable that distinguished various dialects of Old English for nouns that referred to topological features. Finally, a major impetus toward the breakdown of the grammatical gender system of Old English was early evidence of rampant variability in the gender of anaphoric pronouns when referring to animate antecedents of either sex. Texts abound with varying use, even within the same text, between feminine or neuter anaphoric pronouns that refer back to the same antecedent (e.g., the forms wif "woman" or maegden "maiden", which was classified as neuter in Old English, would elicit the use of either neuter hit "it" or feminine sio "she" anaphoric pronouns).

In addition to an already weak" grammatical gender system, one of the major internal factors that has been traditionally purported to contribute to the loss of grammatical gender in English is the leveling of distinctions among inflectional endings.

\footnotetext{
9 The development of gender in the languages of Deviating Language Group A would be an interesting topic for a separate paper, especially since these are seemingly the only ones of all IndoEuropean languages that have followed this pattern.

${ }^{10}$ The reason for tracing the development of gender back to Early Proto-Indo-European is, as will be seen later in this paper, to demonstrate the changing nature of gender within one language family between what the author terms as either more or less semantic transparency.
} 
All of these factors, more internal to the Old English gender "system", were most likely at play simultaneously to the following, more external, events. The period between Old and Middle English can be characterized as one of radical borrowing of loan words from the Norman variety of French as well as from the Scandinavian language of Old Norse ${ }^{11}$. An unprecedented number of new words were absorbed relatively quickly into the English language and in many cases replaced former Anglo Saxon words in the English lexicon. Although seeming on the surface to be a mere lexical phenomenon, this change in Old English vocabulary would subsequently set in motion a series of linguistic events that probably left speakers of developing English in a highly confusing situation where nouns with varying genders competed for adoption. Speakers in this situation would have no choice but to ultimately abandon grammatical gender for the more transparent, natural gender in use today.

This explanation for the eventual loss of grammatical gender seems quite reasonable. However, the gender of a noun in Modern English only surfaces when combined with an anaphoric pronoun that is marked for gender. If this is what happens in Modern English, might we be overlooking an important phenomenon in Old English if we in fact disregard the activity of personal pronouns?

The following section reveals what happens when we consider the gender system of not only nouns, but also pronouns, in Old and Middle English.

\section{Findings/Results}

Semantic Gender in Nouns and Pronouns in Modern English

Having lost all its historical affiliation with grammatical gender in nouns, Modern English has assumed a completely semantic, or "natural", interpretation of gender is evidenced when nouns appear with their corresponding anaphoric pronouns as illustrated in Figure 1.

Figure 1. How Gender Surfaces Through Anaphoric Pronouns in Modern English<smiles>[13CH3]</smiles>

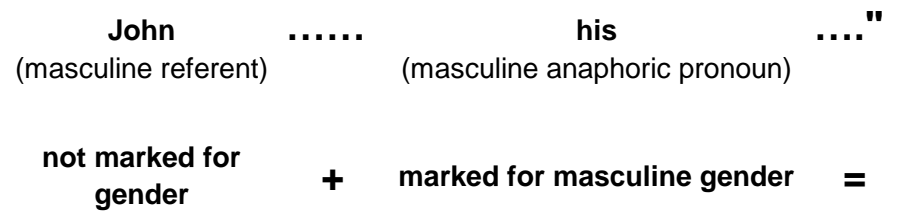

Source: Author.

\footnotetext{
${ }^{11}$ Although borrowing directly from Latin took place into English at this time as well, the author of this paper questions the impact that Latin loans may have had on the reduction of English's gender system, since loan words of direct Latin origin were highly specialized and did not replace everyday Anglo Saxon words to the same extent (if at all) as French and Scandinavian had.
} 


\section{Semantic and Grammatical Gender in Old English Nouns}

Compared to Modern English, the gender of nouns in Old English had a much more complicated configuration. Unlike Modern English, both nouns and pronouns carried marked gender which, as seen later, could work either in support of each other or separately. Secondly, gender in Old English could be either semantic (natural) or grammatical. Table 4 depicts the difference between gender systems for nouns in Old English and Modern English.

Table 4. Nominal Gender in Old English versus Modern English

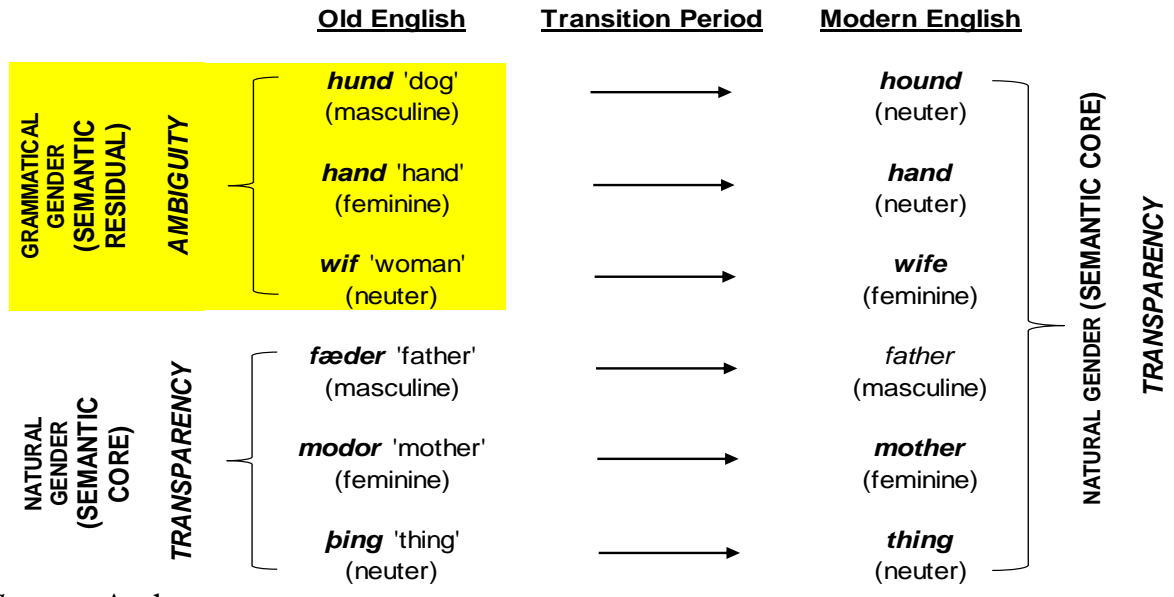

Source: Author.

Over $80 \%$ of the entire noun inventory of the Helsinki corpus refers to people. While some of these nouns are marked for semantic or natural gender (such as mann "man" (masculine), faeder "father" (masculine), ides "woman" (feminine), modor "mother" (feminine), and ping "thing" (neuter), etc.); others are arbitrarily marked for grammatical (not semantic) gender. For these words, unlike in Modern English, meaning does not determine their gender. Figure 2 visually compares the interplay between natural and grammatical gender systems for nouns in both Old English and Modern English.

Figure 2. Interplay of Semantic versus Grammatical Gender in Old English and Modern English Nouns

Old English

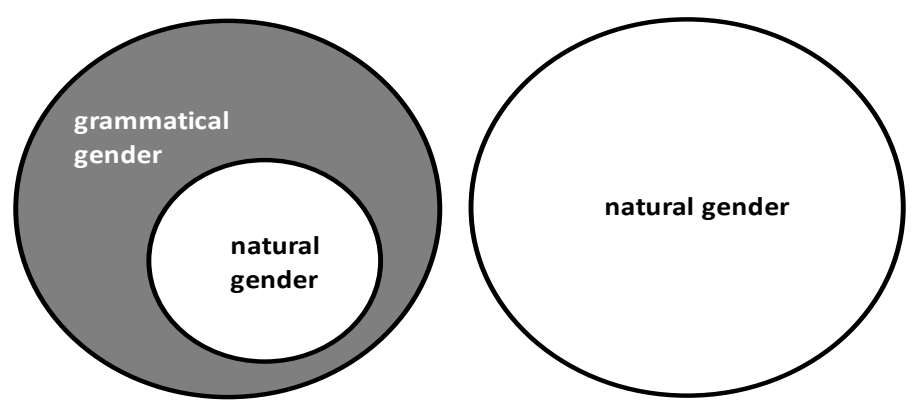

Source: Author. 
More interesting here than the particular gender assigned to given nouns in Old English is the way that nouns marked for grammatical gender behaved in Old English when they were followed by anaphoric pronouns. After all, this is the environment in Modern English where we see true semantic gender come alive. Why would it not be interesting to see what happens in comparable circumstances in Old English? To do this, in the following sections we will look at the behavior of both animate and inanimate nouns in the environment of their corresponding anaphoric pronouns.

\section{Pronominal Gender Marking of Old English Animate Nouns}

Table 5 lists some of the most common animate nouns in the Helsinki corpus whose grammatical gender does not match semantic gender, as well as their corresponding distribution of anaphoric pronouns. Striking about these data is that despite the grammatical gender assigned to each word, the preferred gender of the pronoun following the given noun is semantic.

Table 5. Agreement Patterns in Old English for Animate Nouns

\begin{tabular}{lll}
\hline Antecedent noun & Gender & Pronoun summary \\
wifmann 'woman' & (masculine) & 16 feminine;2 masculine \\
maegden 'young woman, maiden' & (neuter) & 25 feminine \\
wif 'woman' & (neuter) & 116 feminine; 1 masculine-neuter; 1 neuter \\
bearn 'child' & (neuter) & 1 neuter; 2 masculine; 5 masculine-neuter \\
cild 'child' & (neuter) & 10 neuter; 6 masculine; 8 masculine-neuter \\
\hline
\end{tabular}

Source: Curzan 2003.

The data in Table 5 illustrate perhaps one of the most intriguing findings of this study regarding the gender of anaphoric pronouns because, despite the semantically unpredictable, grammatical gender of their corresponding antecedents, they tell us that in the mind of the speaker of Old English, or at least certainly in the minds of the writers of the documents in the corpus, these animate nouns had an overarching, conceptually semantic gender despite their discrepant grammatical gender form. An example of this use appears in Ælfric's translation of Genesis 3: 1-19, the Fall of Man (Mitchell and Robinson 2011), when telling the story of Adam and Eve's destruction, Elfric in describing Eve, chooses the word wif for "woman" which is neuter. However, he uses feminine pronouns such as hire and hēo exclusively thereafter to refer to her:

[13] God cwæð tō ðām wīfe (grammatically gendered neuter animate noun): "Hwī dydestū ðæt?" Hēo (feminine anaphoric pronoun) cwæð: "Sēo nǣdre bepǣhte mē and ic̀ ǣtt." 
God said to the woman: "Why did you do that" She said: "the serpent deceived me and I ate"

[14] God cwæð tō ðǣre nǣddran: "For ðan ðe ðū ðis dydest, ðū bist āwyrged betweox eallum nȳtenum and wildēorum. Đū gāst on ðīnum brēoste and etst ðā eorðan eallum dagum ðīnes līfes.

God said to the serpent: "Because you did this you will be cursed among all animals and wildlife. You walk on your breast and eat the earth for every day of your life"

[15] İ́ sette fēondrǣdenne betwux ðē and ðām wīfe (grammatically gendered neuter animate noun) and ðīnum ofspringe and hire (feminine anaphoric pronoun) ofspringe; $\boldsymbol{h} \overline{\boldsymbol{e}} \boldsymbol{o}$ (feminine anaphoric pronoun) tōbrȳtt ðīn hēafod and ðū syrwst onġēan hire (feminine anaphoric pronoun) hō."

I establish enmity between you and the woman and your offspring and her offspring. She crushes your head and you plot against her heel.

\section{Pronominal Gender Marking in Old English Inanimate Nouns}

The second remarkable finding among the Helsinki data in terms of pronominal gender marking is that despite a preference among animate nouns for semantically gendered pronouns corresponding to a grammatically gendered referent, this same trend was not found to occur for inanimate nouns, exhibiting precisely the opposite. Table 6 shows that in the case of inanimate nouns, anaphoric pronouns tended to agree with the grammatical gender of referent nouns.

Table 6. Anaphoric Agreement Patterns between Old English Inanimate Nouns and Anaphoric Personal Pronouns

\begin{tabular}{|c|c|c|c|c|c|c|c|c|c|}
\hline \multirow[b]{2}{*}{ Noun } & \multicolumn{3}{|c|}{$\begin{array}{c}\text { OE II } \\
\text { (850-950 AD) } \\
\text { Corresponding Pronoun }\end{array}$} & \multicolumn{3}{|c|}{$\begin{array}{c}\text { OE III } \\
\text { (950-1050 AD) } \\
\text { Corresponding Pronoun }\end{array}$} & \multicolumn{3}{|c|}{$\begin{array}{c}\text { OE IV } \\
\text { (1050-1150 AD) } \\
\text { Corresponding Pronoun }\end{array}$} \\
\hline & m & $f$ & $n$ & m & $f$ & $\bar{n}$ & m & $f$ & $n$ \\
\hline m & $87.80 \%$ & $0 \%$ & $12.20 \%$ & $82.80 \%$ & $1.30 \%$ & $16 \%$ & $79.50 \%$ & $11.40 \%$ & $9.10 \%$ \\
\hline f & $2.10 \%$ & $87.10 \%$ & $10.70 \%$ & $0.60 \%$ & $83.40 \%$ & $16 \%$ & $2 \%$ & $86.30 \%$ & $11.80 \%$ \\
\hline $\mathbf{n}$ & $14.20 \%$ & $0.60 \%$ & $85.20 \%$ & $2.20 \%$ & $0 \%$ & $98 \%$ & $4.70 \%$ & $1.60 \%$ & $93.80 \%$ \\
\hline
\end{tabular}

Source: Curzan 2003.

From the data in Table 6, we can make several immediate observations about selection of anaphoric pronouns for Old English inanimate nouns: 1) The most prominent tendency for selection of an anaphoric pronoun for an inanimate noun referent is to choose the same gender as the grammatical gender of the referent noun (i.e., if it is masculine, pick masculine; if feminine, 
feminine; and if neuter, neuter). 2) If the anaphoric pronoun selected for an inanimate noun referent that is marked for masculine or feminine grammatical gender is not of the same grammatical gender, then it will most likely be neuter; and 3) If the anaphoric pronoun selected for an inanimate noun referent that is marked for neuter grammatical gender is not of the same grammatical gender, then it will most likely be masculine, and in rare cases, feminine.

The path of inanimate nouns in terms of holding out to be the only vestige of grammatical gender, at least as far as anaphoric pronouns are concerned, is important because it helps explain what later happens to them in early Middle English. As we indicated above, the second most popular route that anaphoric pronouns take in the Old English period for grammatically gendered inanimate nouns is the neuter variety. This would appear to be the semantic alternative to the grammatical gender of the noun, thus suggesting movement toward a more semantic realization of the gender of the noun. This might have happened because of pressure caused by masculine and feminine grammatically gendered animate nouns that, as we have seen, already preferred the semantic gender in their anaphoric pronouns.

One example is from King Alfred's preface to the translation of Gregory's Pastoral Care (North et al. 2014) when Alfred uses the word wisdom (grammatically gendered masculine) and follows in the same paragraph with both masculine hiene and neuter hit anaphoric pronouns.

"Gode almihtegum sie ðonc ðatte we nu anigne onstal habbað lareowa. Ond for ðon ic ðe bebiode ðat ðu do swa ic geliefe ðat ðu wille, ðat ðu ðe ðissa woruldðinga to ðam geametige swa ðu oftost mage, ðat ðu ðone wisdom (grammatically gendered masculine inanimate noun) sealde ðœr ðœr ðu hiene (masculine anaphoric pronoun) befastan mage, befaste. Geðenc hwelc witu us ða becomon for ðisse worulde, ða ða we hit (neuter anaphoric pronoun) nohwaðer ne selfe ne lufodon ne eac oðrum monnum ne lefdon!"

Thanks be to God Almighty that we have any teachers among us now. And therefore I command thee to do as I believe thou art willing, to disengage thyself from worldly matters as often as thou canst, that thou mayest apply the wisdom which God has given thee wherever thou canst. Consider what punishments would come upon us on account of this world, if we neither loved it (wisdom) ourselves nor suffered other men to obtain it: we should love the name only of Christian, and very few of the virtues.

Later in the same passage, Alfred refers to sio lar (grammatically gendered feminine) as hit (neuter):

"Ac ic ða sona eft me selfum andwyrde ond cwað: 'Hie ne wendon ðatte afre menn sceolden swa reccelease weorðan ond sio lar (grammatically gendered feminine inanimate noun) swa oðfeallan; for ðare wilnunga hie 
$\underline{\text { hit }}$ (neuter anaphoric pronoun) forleton, ond woldon ðat her ðy mara wisdom on londe ware ðy we ma geðeoda cuðon."'

But again I soon answered myself and said: "They did not think that men would ever be so careless, and that learning would so decay; through that desire they abstained from it, and they wished that the wisdom in this land might increase with our knowledge of languages."

\section{Pronominal Gender Marking of Middle English Inanimate Nouns}

By early Middle English, we see a dramatic spurt in the Helsinki texts where grammatically gendered inanimate pronouns start to gravitate toward the neuter gender for their anaphors, making their way to the Modern English system where neuter anaphors will take over completely. Table 7 shows the distribution of agreement patterns between inanimate grammatically gendered nouns with their possible anaphors.

Table 7. Anaphoric Agreement Patterns between Early Middle English Inanimate Nouns and Their Personal Pronouns

\begin{tabular}{|c|c|c|c|c|c|c|c|c|}
\hline \multirow{3}{*}{ Noun } & \multicolumn{8}{|c|}{$\begin{array}{l}\text { Early Middle English } \\
\text { (1150-1250 AD) } \\
\text { Corresponding Pronoun }\end{array}$} \\
\hline & \multicolumn{2}{|c|}{ m } & \multicolumn{2}{|c|}{$f$} & \multicolumn{2}{|c|}{$\mathrm{n}$} & \multicolumn{2}{|c|}{$m-n$} \\
\hline & Occurrences & $(\%)$ & Occurrences & (\%) & Occurrences & (\%) & Occurrences & $(\%)$ \\
\hline $\mathrm{m}$ & 47 & (33.1\%) & 18 & $(12.7 \%)$ & 66 & $(46.5 \%)$ & 11 & $(7.7 \%)$ \\
\hline$f$ & 3 & (1.1\%) & 151 & $(55.3 \%)$ & 104 & (38.1\%) & 15 & $(5.5 \%)$ \\
\hline $\mathrm{n}$ & 0 & $(0 \%)$ & 13 & $(5.0 \%)$ & 236 & (91.5\%) & 9 & (3.5\%) \\
\hline
\end{tabular}

Source: Curzan 2003.

Table 7 shows neutrally gendered anaphoric pronouns are on the increase, making inroads toward establishing semantic or "natural" gender as the norm for inanimate pronouns as well. An important note to make here is that, according to Table 7, the use of the neuter pronoun for feminine-gendered inanimate antecedents is not taking hold as quickly as it is for masculinegendered inanimate antecedents.

\section{Discussion}

Old English and Corbett's Notion of Core versus Periphery

At first glance, gender in Old English nouns, when taken alone and not considering their interaction with other parts of the sentence, seems to be either natural or grammatical, the two exclusive of each other. In other words, in terms of Corbett's (1991) theory of core versus periphery, Old English nouns whose 
gender could be surmised from the meaning of the word appeared to exist in the core of the gender system, while those whose gender could not be inferred from meaning appeared to exist in the periphery of the gender system (Figure 2 ). Figure 3 is a revised representation of the gender system, describing both noun and pronoun systems as opposed to viewing nouns alone. The Helsinki corpus of Early Middle English showed gravitation from an earlier phase in which inanimate nouns selected pronouns whose grammatical gender matched that of the noun to a later phase where neuter pronouns were selected more often, in other words, natural gender.

Figure 3. Revised Representation of the Interaction between Nominal and Pronominal Gender Systems in Old English

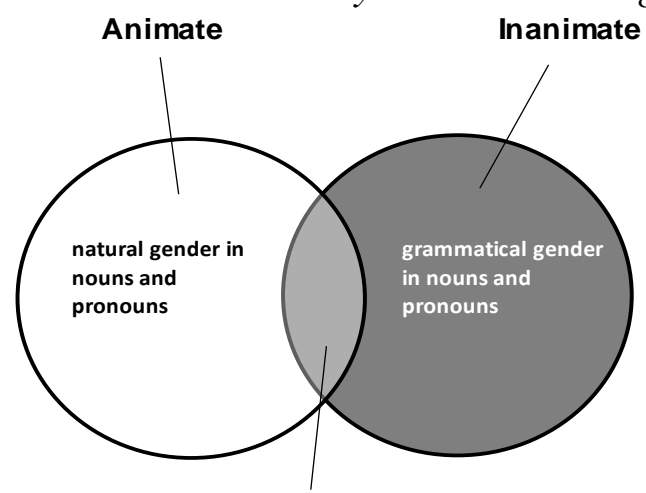

Animate

grammatical gender

in nouns/natural

gender in pronouns

Source: Author.

Figure 4. Interaction between Nominal and Pronominal Gender Systems in Early Middle English

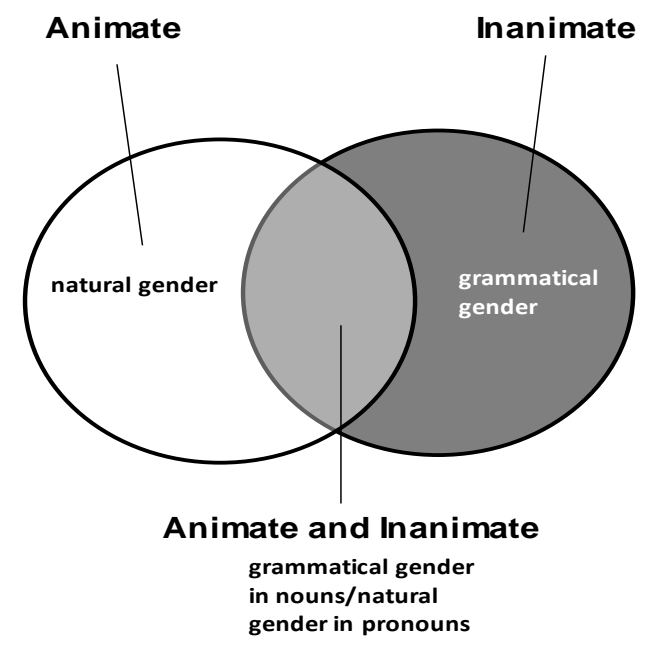

Source: Author. 
These new figures, showing both a dynamic and predictable interface between nouns and pronouns in both Old English and early Middle English, suggest that the original diagrams presented solely for nouns in Figure 2 and Table 4 are not adequate to describe what is happening with gender at the sentence level in Old English. Figures 3 and 4, rather, are better explanations. The new figures visually suggest a gradual eclipsing over time of grammatical gender by natural gender, helping to explain the shift from the two systems to the one that we have today.

\section{Similarity in Gender Systems between Early Proto-Indo-European and Modern English with Regards to Semantic Transparency}

In this section of the paper, I will draw upon the data and previous research elaborated in the first two sections to argue for a similarity in what I will call semantic transparency between the gender systems of Early ProtoIndo-European and Modern English. Figure 5 suggests a visual summary of the development of the Modern English gender system in terms of semantic transparency from the earliest days of Proto-Indo-European. This diachronic bird's eye view provides a unique perspective that allows us to see patterns that might not be as evident when looking individually at the various systems vacuously on their own.

The first critical observation to make is that the Early Proto-Indo-European noun class system originally had greater semantic transparency-indicated in the figure by a clear surrounding box - that was based on the level of animacy of the referent. This transparency was greatly reduced over time by Late ProtoIndo-European when the newly created "feminine" gender was an opportunity for formerly neuter abstract or collective concepts to become arbitrarily associated with a feminine gender. Figure 5 visually portrays this phenomenon of what I will call minimization ${ }^{12}$ by gray shading. As the figure further suggests, this period of "minimalized" semantic transparency continues through the periods of Proto-Germanic and Old English.

A second important observation that one can make is that of a seemingly reverse phenomenon occurring in the period from Old English through Modern English as had occurred from Early Proto-Indo-European through Late ProtoIndo-European. In other words, as Figure 5 suggests, the trend of minimization found between Early and Late Proto-Indo-European (and visually represented by the movement from a clear box to a gray box) is reversed in the period from Old to Modern English (and visually represented by the movement from a gray box to a clear box). I will call this reverse process maximization ${ }^{13}$.

\footnotetext{
12 The author chooses to use the notion of "minimization" rather than "disappearance" because, as seen in an earlier section of this paper, typologists have maintained that all languages, even those with arbitrary assignment of gender, still retain a semantic core of nouns for which gender can be predicted from their meaning.

${ }^{13}$ The author does not feel this term is as adequate for this phenomenon as "minimization" is for the alleged process in Proto-Indo-European. However, for lack of a better term, I use it to emphasize the reverse trend from less to greater semantic transparency.
} 
Curiously enough, the semantic transparency of our natural gender system in Modern English, as opposed to the arbitrariness of a grammatical gender system of Old English, can be likened to the original transparency of the distinction of animacy in Early Proto-Indo-European. I therefore maintain that, although the two systems seem very different in the sense that the focus in modern English is the biological sex of the referent and that for Indo-European was animacy, linguistically speaking the two systems are very similar when it comes to the notion of semantic core. In other words, both systems were configured so that gender (in the case of modern English) or noun class (in the case of Early Proto-Indo-European) was predictable from the meaning of the noun in question.

Figure 5. The Evolution of Gender from Proto-Indo-European to Modern English

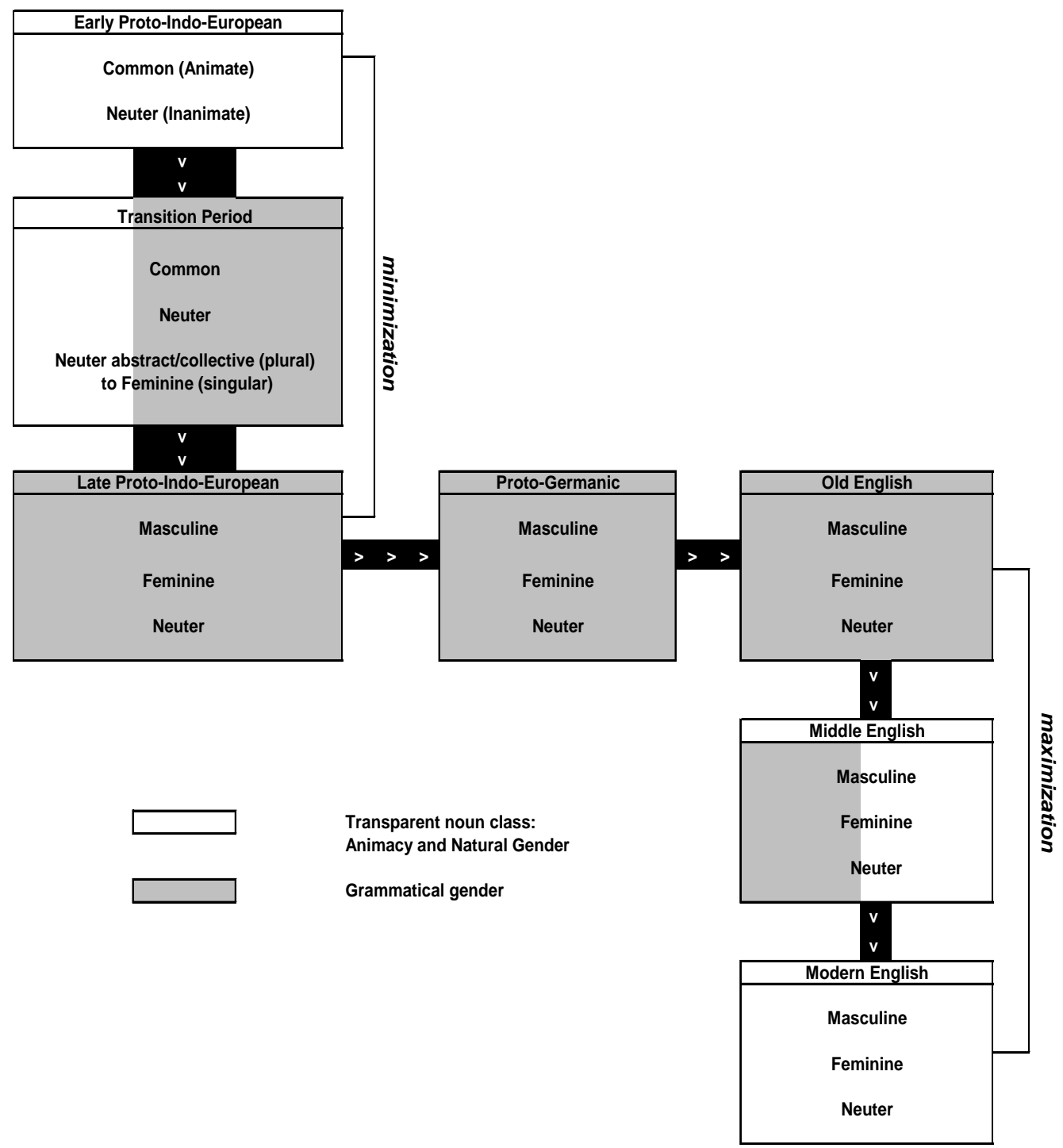

Source: Author. 


\section{Conclusions}

Modern English has come to rely solely on natural gender and we know this only because of the continued use of gender-distinct personal pronouns, the latter being the only morphemes in our language that carry gender at all, nouns having lost all trace of marked gender ${ }^{14}$. The task looking at the behavior of Old English pronouns with regard to their antecedents proved to be enlightening in terms of gender assignment and provided new insights into the real gender system of Old English. Despite the grammatical gender marking of a given animate noun, its anaphoric pronoun virtually always agreed with the noun in natural gender. This has important historical implications for the development of gender from Old to Middle English, and then subsequently to Modern English. In the first place, if animate nouns always took "natural" anaphors, then it helps explain the origin of our exclusively "natural" gender system of today, rather than trying to find a seeming connection between loss of grammatical gender and other distantly related phenomena like the leveling of inflectional forms or the alleged existence of an already "weak" nominal gender system. Secondly, inanimate nouns that the majority of times took pronouns that agreed with their grammatical gender, at other times opted for the neuter. This tells us that even for inanimate nouns there was some notion of "natural" gender.

An important implication of these findings is that in the mind of native Old English speakers, at some abstract level, nouns came "alive" so to speak when they were used in sentences so that despite the discrepant grammatical gender of an animate noun, the "naturally" gendered anaphoric pronoun was selected over the corresponding grammatical one. And even with the preponderance of grammatically gendered pronouns that appeared in the case of grammatically gendered inanimate nouns, data shows that an option existed for the neuter to be used at times instead of the pronoun corresponding to the noun's grammatical gender.

This study proposes a complex animacy-based configuration for Old English, consisting of: 1) a noun class system for inanimate nouns corresponding more closely to the traditional notion of grammatical gender, where the noun form rather than its meaning determined the class it belonged to and what pronouns it would govern; and 2) a natural gender system for animate nouns and to some degree some inanimate nouns, that worked very much like our natural gender system does today.

A possibility for further research is to look beyond pronouns at the behavior of other items, such as determiners, quantifiers, and adjectives. An initial hypothesis would be that closer proximity of these items to the noun might restrict its gender to that of the noun, arguing one of the possible explanations for application of natural gender to animate anaphors being the mere distance between the noun and its anaphor. In other words, agreement between nouns and modifiers in Old English noun phrases such as ðat wif or "that/the woman"

\footnotetext{
${ }^{14}$ Excepting, of course, such derivational morphemes such as - ess in such words as "actress", or less frequently -ette in such words as "majorette".
} 
might be explained by the nearness of the modifier to its noun. It would also be interesting to examine the behavior of adjectives that modify nouns such as wif, located either contiguously or at some distance from the noun, to see whether proximity, or lack thereof, between noun and corresponding adjective, would make a difference in determining grammatical or semantic gender of the resultant form.

A final implication of these findings is in the area of pedagogy. The behavior of nominal and pronominal gender systems of Old English might be explained differently to students so that they have a better understanding of how these worked in tandem, rather than as two separate systems. The difference in behavior between animate and inanimate nouns in terms of gender of the anaphoric pronoun they select is important to those learning the language, especially in making a seemingly "dead" language more real for them, relating these phenomena to a not entirely different system in their own modern language, creating a rare opportunity of getting into the minds of the Anglo Saxons.

This paper provided a typological overview of gender systems across languages. It demonstrated that some languages have gender, others do not, and that patterns of gender-present and genderless languages tend to be explained by combined genetic and aerial phenomena. The paper then went on to look at gender systems across languages of Indo-European descent and subsequently, only the Germanic languages. A unique trend was discovered within the Germanic family as compared to other Indo-European families.

This paper also traced the development of what is considered natural gender in Modern English from Early Proto-Indo-European times. I demonstrated that by looking at individual snapshots of gender systems within the different periods, certain longitudinal trends began to appear regarding the ratio of nouns belonging to the semantic core to those belonging to the residue. To describe some of these trends, particularly with regard to the evolution of gender in English, I introduced the notions of semantic transparency, minimization, and maximization. To conclude, changes in gender systems, at least as is represented by the development of English, seem to respond to both semantic as well as social motivations.

\section{Gender as a Semantic Phenomenon}

Based on the work of Corbett (1991) and others, we have found that for all languages having gender systems there exists a semantic core of nouns for which gender can be predicted solely from meaning. All other nouns of a given language, for which gender cannot be predicted from meaning alone, are considered part of the semantic residue, and for these, gender is predicted based on more formal (morphological/phonological) characteristics. Over time, for many languages where morphological/phonological characteristics are leveled, a reduction in the number of gender distinctions could follow a number of paths. As we have seen, the trend which is most common for languages 
descending from Indo-European ${ }^{15}$ is the leveling between masculine and neuter genders. As Matasovic (2004) points out, most typologists attribute this trend to the extremely formal similarity between the masculine and neuter genders, which, depending on the path of leveling that took place within particular languages, would contribute to a blurring between these two genders. For other languages, like English, where formal leveling took place between all three genders and so many external linguistic pressures, a different path would take place, that of an increase in semantic transparency, or maximization, where a more natural assignment of gender takes place.

\section{Gender as a Social Phenomenon}

This paper has also looked for cases where the evolution of gender systems may indeed have been motivated by constant pressure to adapt to social and political realities. Matasovic (2004) and others have pointed out that genetic trends in gender can be affected by geographical contiguity with languages of a differing trend. For example, languages of Indo-European descent are typically gender-present languages, however, such Indo-European languages as Armenian, Persian, and some other Western Iranian languages which are geographically located near genderless language families have developed genderless systems. This would suggest that the existence or not of gender systems is at least in part a social phenomenon.

Another instance we have seen where social interaction may have contributed to the development of similar gender systems is in the Germanic languages, where all three Late Proto-Indo-European genders have been maintained, except for the cases of Deviating Language Groups A and B. For the group that we termed Language Group A: East Scandinavian, Frisian, and Dutch, these languages are geographically proximate to each other and all three have followed a particular path shared by no other Germanic, or Indo-European, language for that matter-that of merging masculine and feminine genders into a common gender. This would also suggest, at least in part, a social phenomenon.

\section{Acknowledgments}

The author wishes to thank the University of Northern Colorado for a 2017 Provost Travel Award so that he could present a portion of this paper at the 10th Annual International Conference on Languages and Linguistics in Athens, Greece.

\footnotetext{
${ }^{15}$ This is the path taken by all of the Romance languages (Criado de Val 1972). Originally, my interest in the topic of gender was motivated by this trend and an initial hypothesis that the masculine-feminine distinction characteristic of this path might be due to an overall trend or preference for languages to move from a grammatical to a more natural gender configuration. However, further research into the topic yielded the conclusion explained above, that is, this change was motivated by none other than the leveling between the formally similar masculine and neuter genders.
} 


\section{References}

Baldi P (2011) "Indo-European Languages". In B Comrie (Eds.), The World's Major Languages. Oxford: Oxford University Press.

Campbell A (1983) Old English Grammar. Oxford: Oxford University Press.

Corbett G (1991) Gender. Cambridge: Cambridge University Press.

Criado de Val M (1972) Fisonomía del idioma español: sus características comparadas con las del francés, italiano, portugués, inglés y alemán (Physiognomy of the Spanish language: its characteristics compared to French, Italian, Portuguese, English and German). Madrid: Saeta.

Curzan A (2003) Gender Shifts in the History of English. Cambridge: Cambridge University Press.

Fortson BW (2005) Indo-European Language and Culture: An Introduction. London: Blackwell Publishing.

Gray RD, Atkinson QD (2003) Language-tree divergence times support the Anatolian theory of Indo-European origin. Nature 426: 435-439

Kitson P (1990) On Old English nouns of more than one gender. English Studies 71: $185-221$.

Matasovic R (2004) Gender in Indo-European. Universitatsverlag: Heidelberg.

Meillet A (1970) General Characteristics of the Germanic Languages: Miami Linguistics Series No. 6. University of Miami Press.

Mitchell B, Robinson F (2011) The Fall of Man (Genesis 3:1-19). A Guide to Old English, Eighth Edition. London: Wiley-Blackwell.

North R, Allard J, Gillies P (2014) King Alfred's Prefaces: Preface to the translation of Gregory's Pastoral Care. Longman Anthology of Old English, Old Icelandic, and Anglo-Norman Literatures. London: Routledge.

Quirk R, Wrenn CL (1957) An Old English Grammar. Holt, Reinhart and Winston, Inc.

Schwink F (2004) The Third Gender: Studies in the Origin and History of Germanic Grammatical Gender. Heidelberg.

Tichy E (1993) Kollectiva, Genus feminum und relative Chronologie im Indogermanischen, in KZ 106: 1-19. 
Vol. 4, No. 4 Ryan: The Proof is in the Pronoun... 